\title{
Mapping Ancient Heritage Narratives with Digital Tools
}

\author{
Anna Foka, \\ DH Uppsala, Department of ALM, Uppsala University, \\ Humlab, Umeå University \\ anna.foka@abm.uu.se \\ David A. McMeekin
}

School of Earth and Planetary Sciences, School of Electrical Engineering, Computing and Mathematical Sciences, Curtin University, Perth, Australia david.mcmeekin@curtin.edu.au

Kyriaki Konstantinidou

Humlab, Umeå University

kyriaki.konstantinidou@umu.se

Nasrin Mostofian

Department of Computational Linguistics, Uppsala University

Affiliate of Humlab, Umeå University

nasrin.mostofian@gmail.com

\section{Elton Barker}

Department of Classical Studies, the Open University Elton.Barker@OPEN.AC.UK

O. Cenk Demiroglu

Department of Geography, Umeå University

cenk.demiroglu@umu.se

Ethan Chiew

School of Electrical Engineering, Computing and

Mathematical Sciences, Curtin University, Perth, Australia

Ethan.Chiew@student.curtin.edu.au

How to cite this book chapter:

Foka, A., McMeekin D. A., Konstantinidou, K., Mostofian, N., Barker, E., Demiroglu, O. C., Chiew, E., Kiesling B. and Talatas L. 2021. Mapping Ancient Heritage Narratives with Digital Tools. In: Champion, E. M. (ed.) Virtual Heritage: A Guide. Pp. 55-65. London: Ubiquity Press. DOI: https://doi.org/10.5334/bck.f. License: CC-BY-NC 


\author{
Brady Kiesling \\ ToposText, Athens, Greece \\ Affiliate of Humlab, Umeå University \\ westtothesea@hotmail.com \\ Linda Talatas \\ University Paris 1 Panthéon-Sorbonne \\ Affiliate of Humlab, Umeå University \\ xindara@gmail.com
}

\begin{abstract}
How does 'digital' apply to ancient pasts? Digital methods, especially methods relating to identifying, visualizing, and analysing spatial data, have become increasingly important within the fields of classical literature, archaeology, and heritage. On the one hand, literary narratives offer potentially different ways of representing space and place than the usual cartographic maps to which we have become accustomed. On the other hand, by virtue of being able to locate cultural artefacts in space - where they were found, through whose hands they have passed, where they reside now, where they were produced and circulated - it becomes possible to construct biographies or even itineraries of objects that offer richer ways of understanding their use and agency.

Unique in all classical literature, Pausanias's second-century CE Periegesis Hellados presents an example of both types of spatial representation - a narrative that describes places of interest in the Greek landscape as well as the notable objects found there. This chapter discusses some of the ways in which Pausanias's narrative of Greek heritage is good to consider when attempting to use digital methods for analysing the entanglements of place, people, and objects in a textual geography.
\end{abstract}

\title{
Introduction
}

Digital cartography and geographic information systems (henceforth GIS) have been used for decades to connect primary sources (such as literary, archaeological, historical, and heritage evidence) to spatial data and further 
visualise them in cartographic interfaces. The spatial turn in humanities disciplines has been extensively applied to the study of ancient lifeworlds and has become increasingly important within the fields of classical philology, archaeology, and heritage (Barker et al. 2010; 2012: 185-200; Lundqvist \& Landeschi 2015: 25-27).

GIS is a technological framework for gathering, storing, managing, presenting, and analysing data systematically, as a scientific method (Dunn 2019; Foka et al. 2020: 203-217). Exploring the spatial narratives of objects and peoples opens the possibility to a deeper and broader understanding of the past, where and when they were situated in history as space becomes place, imbued with meaning.

The Barrington Atlas became a modern GIS in 2000, covering Ancient Mediterranean geography, but literary territories are limited to the study of toponyms (place names derived from topographical features). Paladino (2016) notes how the semantic concept of space is not necessarily limited to routes; it can be seas, islands, or lakes. Other words too, may have semantic importance beyond their geographical locations. The importance of engaging with the geographies of artefacts as they transcend through histories and cultures to provide readers with a fuller analysis of provenance ought to be highlighted as object itineraries (Dunn et al. 2019: 253-271). GIS, however, may be limited to the annotation of place as static toponyms, as they do not classify other concepts or entities, such as temporal data, social networks, or movement for example.

Here we focus on the complexity of mining spatial heritage datasets by looking at mining information from languages beyond English. Our case study is Pausanias's Periegesis Hellados (Description of Greece), ${ }^{1}$ a cultural geography of Greece written in the second century CE in Greek and composed essentially by 'the things that deserve to be recorded' (Pausanias, Description of Greece 1.39.3). In this we ought to note that Pausanias wrote at a time of Roman colonisation of Hellenic space and was, as it transpires from his work, particularly interested, even biased, to illuminate his readers on Hellenism and its history across the Mediterranean.

Periegesis has been widely used as a guide within the field of classical archaeology, relating to archaeological or monument locations but further also connecting to the movement and population of sites as well as artefact transportation and composition. It has been, for centuries, treated as an information repository, particularly for the discovery and interpretation of peoples, sites, and, subsequently, for Hellenic heritage artefacts and monuments. The complexity of his description as well as his selective working methods have led to several misunderstandings.

At the dawn of the 20th century, Willamowitz's peripatetic archaeological methods had rejected Pausanias's topography as inaccurate and biased at best. While there are certainly locations described in a selective and biased manner, Pausanias topographical descriptions of larger sites more often match the archaeological record, as demonstrated by the sanctuary of Apollo at Delphi by the École Française d'Athènes and the Athenian Agora by the American School 
of Classical Studies (Cundy 2018: 3). However, Pausanias's description of place does not necessarily map easily on to the archaeological record that emerges through excavation (see Hutton 2005). Instead, Pausanias topographical narrative entails past accounts of the places through which he passes and the objects in space he sees. It is a narrative time machine of sorts, a highly selective process that binds together place, artefact, origin, and purpose in space in disparate historical instances the author narrates.

Epistemologically, the complexity of this time-space matrix illuminates the time-depth problem of the Greek East - that is, by providing ways of compartmentalizing and marking these 'different temporalities of the long-study of urbanism in the Mediterranean East' (Hodder 1993: 279-80; Stewart 2013: 236). Pausanias's Periegesis is a manifestation of literary territories as conceptual and subjective, comprising a specific selection of data. The historicgeographic method has been criticized for the loss of subjective and local variation (Cocq 2008). Similar concerns have been raised by some archaeologists on GIS usage in archaeology, including the suggestion that the technology removes the human, subjective aspects of interpreting data (Conolly \& Lake 2006; see Vassalo et al. 2018 for a review of discussions with respect to the use of 3D GIS).

Nature and culture in their tangible (settlements, artefacts, people) and intangible (movement) forms are thus studied here as spatial extensions and networks of disparate data. The application of data science and information systems does not remove the complexities associated with traditional cartography and even introduces new challenges. The aforementioned case study thus helps identify the validity of digital methods to understand the spatial dimensions of ancient narratives as a research, educational, and dissemination tool. In foregrounding the role of digital technology, this research takes, as its starting point, the inherent statistical bias.

\section{Pausanias' Role: Extracting Heritage Data with Computational Methods}

Heritage more generally, has come to mean the events, materials, or processes that have a special meaning for the memory and identity of certain groups of people. Heritage is a concept that springs from modernity's ambitions in ordering, classifying, and categorising, but also the idea of a threat or a risk that forces humanity to recognise identities and their tangible or intangible representation (Harrison 2013). Previous classical scholarship (including archaeology and reception) has examined the text in terms of: narratology of heritage (Akujärvi 2005; Habicht 1985; Pretzler 2007); identity and memory (Alcock 2001; Arafat 1996); and ethnicity and religion (Konstan 2001). Pausanias's spatial description of the towns, buildings, and monuments through which the reader moves has been widely used as a guide for interpreting those sites and their archaeology and classical heritage (Dyson 1988; 2006: 79, 251-254; Shanks 1996: 49-52. Cf. Habicht 1985: 70-77. Cf. Stuart 2013: 236). 
We discuss here the potential for a digital conversion and rendering of this spatial narrative of Greek monuments and artefacts, using a number of methods, such as Recogito, a platform for semantic annotation of text as well as exploring the possibility for text mining, to tease apart the relationship between movement, space, and memory. In doing so, we group our inquiries into themes, notably examining Pausanias's description of locations of memory through geovisualisation, looking further at the potential for extracting dynamic relations of movement or origin. In what follows, we discuss previous scholarly attempts to geovisualise ancient narratives with digital technology, the complexity of mining Periegesis Hellados for spatial data, our close reading data-gathering methods, and our semantic annotation strategy and tools, notably the platform Recogito, and future plans.

\section{Mapping Meaningful Journeys in Contemporary Cartographic Environments}

Geographic in this case means a 'georeference', an actual location on the Earth, a place that can be represented on a cartographic map. There are a number of complexities associated with this endeavour. First, a location described within a text may have a mythological location. One example is 'Hyperborea', which is a mythical 'northern' (assuming of Greece) location that Pausanias refers to multiple times within the text and in relation to other real places. According to Pausanias's Description of Greece, 5. 7. 8, Hyperboreans were people who lived above Boreas, another name for Thrace, but in maps based on points and descriptions given by Strabo Hyperborea, shown interchangeably as a peninsula or an island (Strabo 11.4.3). This makes the place altogether impossible to locate as a point on a conventional map. Within the Recogito built-in maps, Hyperborea is only conventionally located (Figure 10).

A second issue is the very temporality of cartographic environments. A space becomes a place because of specific temporal parameters. Whole towns relocate and change names over time, and often colonies have identical names to the 'motherland'. One example of this in Pausanias is the town of Achaia, which according to Pausanias (7.1.1) himself refers to the land between Elis and Sicyonia, reaching down to the eastern sea, in his contemporaneity called Achaia after the inhabitants, but previously named Aegialus. Another methodological issue is using temporal data; libraries for the parsing of ancient dates are scarce and incomplete, so the present options are to draw upon time period and data gazetteers such as PeriodO (http://www.perio.do) and Trismegistos (https://www.trismegistos.org).

A third issue is environmental change. For example, in a contemporary map one might not be able to identify a now-submerged island or a drought river. One example is rivers in Asia minor that, while discussed in Pausanias's book seven, 'cannot be identified in the digital atlas of the Roman empire, or even the submerged island Vordonisi in the sea of Marmara. Thus, mapping an already rich text with heritage data into a cartographic environment becomes challenging. The 


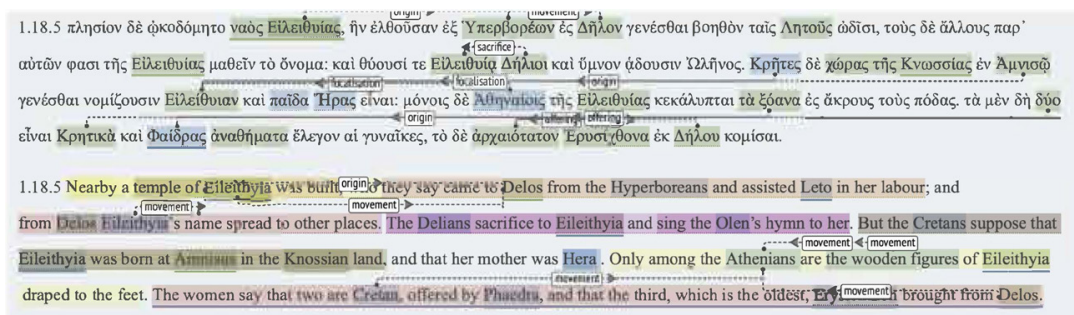

Figure 9: Greek and English translation of passage 1.18.5 of Pausanias's Periegesis Hellados with different relational annotations to display movement and origin in the semantic annotation platform Recogito. This displays the complexity of mapping narratives of heritage in different languages.

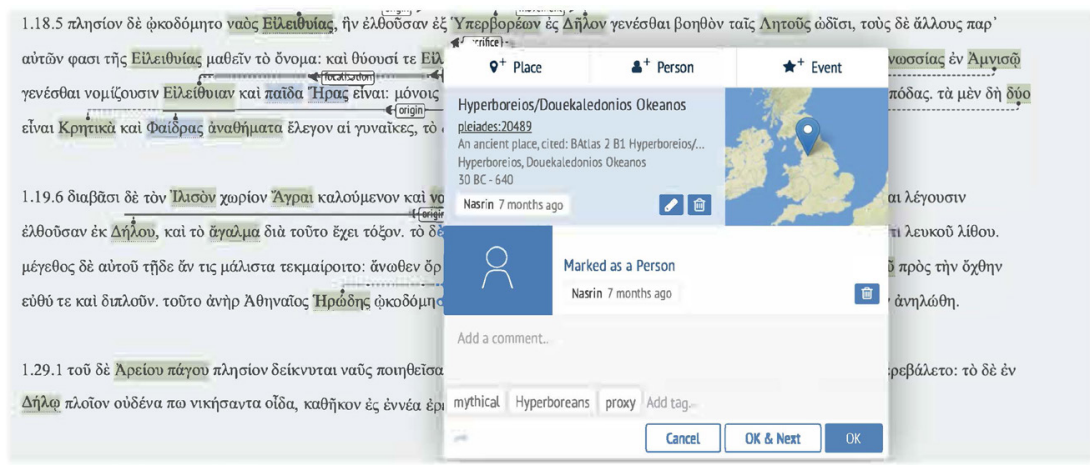

Figure 10: A conventional (and incorrect) mapping location for mythical Hyperborea as found in the built-in cartographic system of Recogito.

scholar must decide how this may be represented in a spatial manner. The decision may even be made to not represent it. However, a decision must be taken.

\section{Working Method: Recogito and Some Preliminary Results}

Currently, we have uploaded Pausanias's ten books to the local Umeå university server's instance of Recogito (http://recogito.humlab.umu.se) in order to curate the document as a database of heritage-spatial information. The working method is to align words to appropriate georeferenced data, found in several gazetteers. The most complete gazetteer for spatial data of the Balkan peninsula and the Eastern Mediterranean is Pleiades. For more granular topographic and heritage data we additionally use Topostext gazetteer. For art historical artefacts and monuments finds we use Judith Binders Art History Gazetteer and the German Archaeological Institute's (DAI) gazetteer for archaeological finds (e.g., districts, temples, statues, etc.). If no appropriate match can be 


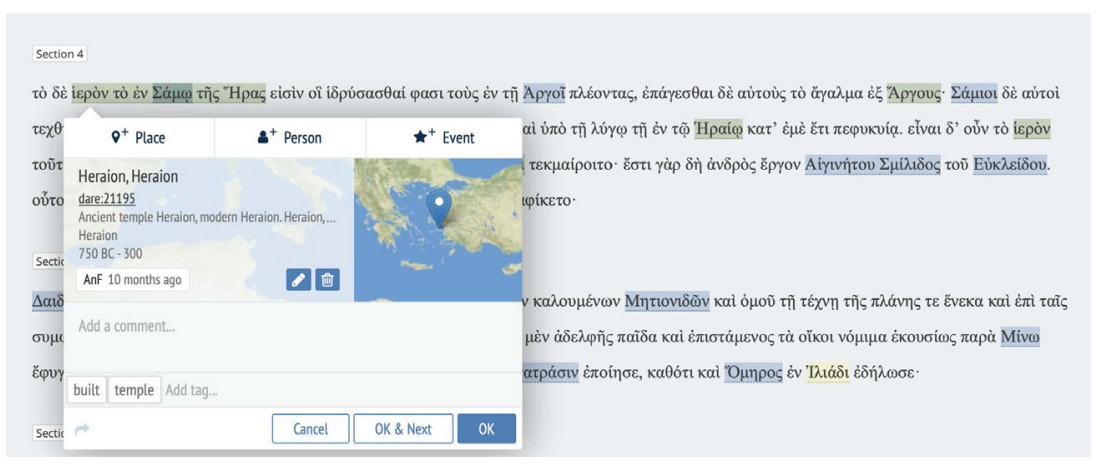

Figure 11: Recogito interface with marked- up, identified, and DARE gazetteer alignment of the Ancient Temple of Hera in the island of Samos (Heraion) including additional free tags such as 'build' and 'temple'.

found, then we use the yellow flag option and the comments box for further details that are then returned to the gazetteer developers. Recogito supports further free tagging, that is, enriching each word with additional information (see Figure 11).

To this, we have a working ontology: a structured list of information pertaining to structuring and organising cultural heritage words and then enriching them with metadata. For marking spatial entities, we use the Place entity tab to mark the place in the document. Then, when the pop-up box appears, we align the place reference to an appropriate gazetteer entry using the map or Recogito's automatic matching.

- If the place represents a human footprint on the landscape that denotes heritage data (e.g., city, temple, etc.), we use 'built' to enrich the word.

- If the place represents a physical feature of the landscape (river, sea, mountain, etc.), we use 'physical'.

- If the place represents a conceptual area or territory (e.g., Messenia, 'the Corinthian land' (chora), 'Greece', etc.), we use 'regional'.

- If the place represents a clearly mythical space (e.g., Hades), we use 'mythical'.

- if the place represents an object in space (e.g., statue, xoanon [wooden image], dedication, column, etc.), we use 'object'.

- If the place represents a material (e.g., Phrygian marble, Assyrian fabric) from a provenance other than the object or building it belongs to, we use 'material' - and use relational tagging > 'provenance'.

We further use a second tag:

- For built, further defined as: 'settlement', 'temple', etc.; for physical, further defined as: 'river', 'sea, 'mountain', etc. 


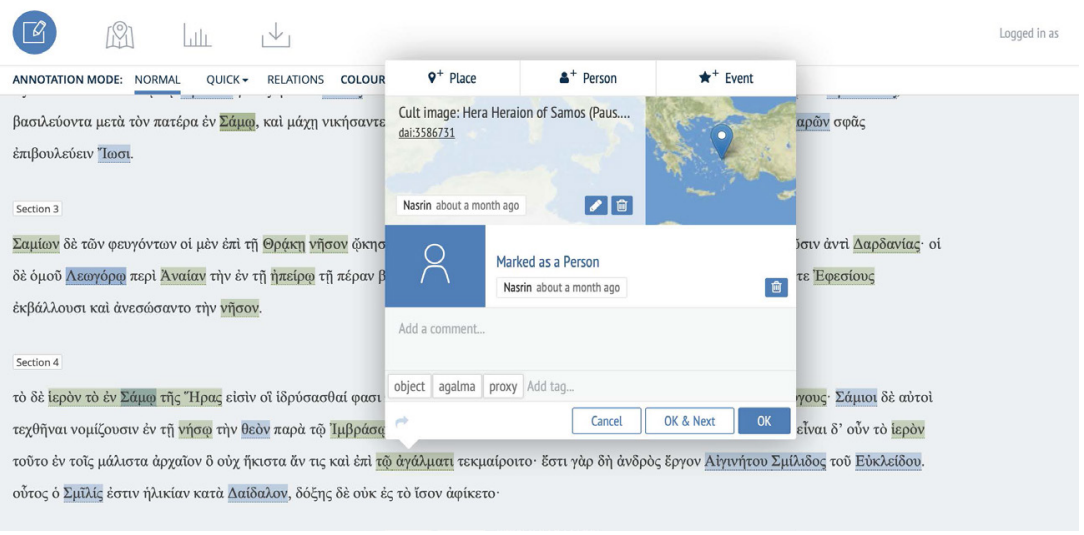

Figure 12: Object identification and tagging in book 7 section 4 of Periegesis, including mark-up and georeference alignment in the DAI gazetteer.

- For regional, further define if further information is given (e.g., 'deme', 'the Corinthian land' (chôra) etc.).

- For mythical, further define using the place mentioned: e.g., 'Hades'.

- When it comes to heritage objects we further define as: 'agalma', 'xoanon', 'anathēma', 'kiōn', etc. (see Figure 12).

Producing a geo-annotated version of Pausanias's Description of Greece means that we will identify and analyse the forms of space within Pausanias's narrative - the ways in which places, monuments, and other objects (heritage data such as sculptures, tombs, etc.) are described in the text, and how the narrative is organized spatially. Using Recogito, the team semantically annotates 'places' using the following method. First, an entity is identified in the text as a place (or object in space). Then it is mapped (where possible) to a global gazetteer. Third, tags are used to provide additional information for, and construct a schema for thinking about, place in more depth, such as: whether the place is physical (a river, mountain, etc.), built (a city, temple, altar, etc.), regional (a wider geographical area), or mythical.

Recogito further supports a range of export formats that can be enriched with additional information as metadata. The options presented in our private instance relate to downloading annotations in CSV, as a data table for importing into spreadsheet software or a GIS. There is a further possibility to download annotations and document metadata as RDF, encoded using Open Annotation and Dublin Core, in JSON-LD, RDF/Turtle and RDF/XML formats. For places, the user is able to download confirmed geo-located places in the document as a GeoJSON FeatureCollection. Geo-located places can finally be downloaded as a KML file, for viewing in Google Earth, for example. We take advantage of this aspect of Recogito to not limit data reuse from the project based upon the GIS or software system one uses. 


\section{Text Mining Possibilities}

When mining text there are considerations that must be taken into account; decisions about these considerations must be made and then acted upon. The first consideration is the original language of the text. Will the text mining take place across the original language or will it occur across the language to which the text has been translated into? In this situation, the original language of the text is Greek. A decision must be made regarding mining the Greek or, for example, the English translation. If it is decided to mine the English translation, this must be documented to clearly identify to the reader that it was a translation and not the original that was mined.

If the original language is to be mined, then this will influence the applied text mining method and algorithm selection. Although this may be obvious to the skilled linguist, it may not be obvious to a novelist and may lead to incorrect conclusions about what text does and does not contain. Different languages are constructed in different ways and hence, in text mining, these must be considered and incorporated into the algorithms to be used.

Here Greek is the original text's language, while English is the book chapter language. Greek is constructed differently from English and hence the text mining algorithms must take this into consideration. Again, perhaps obvious to the linguist but perhaps not obvious to the spatial or computer scientist. In the case of Greek, an inflected language that utilises cases that alter the suffix of the given noun instead of prepositions, the question of text mining becomes a complicated issue. For example, if one needs to mine the term for sculpture, that is 'agalma' (ä $\gamma \alpha \lambda \mu \alpha)$, finding noun in another format (e.g., in genitive possessive: $\dot{\alpha} \gamma \dot{\alpha} \lambda \mu \alpha \tau o \varsigma)$ means that one needs to mine another version of the word that is significantly changed - perhaps for Greek only focusing on the stem, excluding the suffix that denotes a case, for example, $\dot{\alpha} \gamma \dot{\alpha} \lambda \mu$.

The construction of a system permitting automated mining and comparison of the original and translated texts may further enhance the understanding of what the text contains and may highlight possible current era misunderstandings of a text's content.

\section{Conclusions: Dynamic Relations, Spatial Complexity and the Future}

Within the project Digital Periegesis, the task is to enrich character strings, words that have a semantic purpose with spatial data. In this chapter, we discussed the possibilities and complexity for discovering words that denote heritage and then enriching them with relevant data. The team tested several ways to mine and ascribe metadata, most notably working with the semantic platform Recogito. In spite of the complexities in close reading of the text, it is possible, using appropriate cartographic environments and gazetteers, to create a digitally enriched edition of Pausanias's description of Greece. The combination 
of a number of gazetteers for the ancient world as well as the use of an accurate cartographic environment makes the exercise of semantic annotation in Recogito a deep learning process of Hellenic heritage across and beyond the Mediterranean.

During the process of annotation, the importance of data relating to time and people was noticed. It was not only the case that people were being used as proxies for places; Pausanias also showed interest in inventories of people, either by ethnicity, by historical or mythical means, or even by genealogy, as an alternative means of structuring his information. Most importantly, it was observed that Pausanias not only moved through space but through time. LOD methods and tools in the Digital Humanities, however, are currently limited to place. The lack of appropriate LOD 'authority files' for temporal and prosopographical data entities can be further investigated in the future, as well as the possibilities for text mining spatial heritage information. Using the techniques described within, it may be possible to create an interface to map spatial information and consequently, a symbology that will fit the purpose of creating visual maps for historical geovisualisation for Hellenic heritage more generally.

\section{Notes}

1 The project Digital Periegesis (www.periegesis.org) is a collaboration between Humlab at Umeå University, Uppsala University, The Austrian Institute of Technology, The Open University in the UK and the Pelagios Network of Partners. It is funded by the M\&A Wallenberg foundation (2018-22).

\section{References}

Akujärvi, J 2005 Traveller, Narrator: Studies in Pausanias' Periegesis, Stockholm.

Alcock, S E, Cherry, J F, and Elsner, J (eds.) 2001 Pausanias: Travel and Memory in Roman Greece. Oxford.

Arafat, K W 1996 Pausanias' Greece: Ancient Artists and Roman Rulers. Cambridge.

Barker, E, Bouzarovski, S, Pelling, C, and Isaksen, L 2010 Mapping an ancient historian in a digital age: The Herodotus Encoded Space-TextImage Archive (HESTIA). Leeds International Classical Studies, 9(2010): article-no.

Cocq, C 2008 Revoicing Sámi narratives: North Sámi storytelling at the turn of the 20th century (PhD dissertation). Institutionen för språkstudier, Umeå. 
Conolly, J and Lake, M 2006 Geographical information systems in archaeology. Cambridge University Press.

Dunn, S, Earl, G, Foka, A and Wooton, W 2019 The birth of the Digital Object Itinerary. In: Giannini, T. and Bowden J. (eds.) Museums and Digital Culture: New Perspectives and Research. London, 253-271.

Dunn, S 2019 A History of Place in the Digital Age. London: Routledge.

Dyson, S L 1988 The relevance for Romanists of recent approaches to archaeology in Greece, $J R A, 1,143-146$.

Dyson, Steven L 2006 In Pursuit of Ancient Pasts: A History of Classical Archaeology in the Nineteenth and Twentieth Centuries. New Haven: Yale University Press.

Foka, A, Cocq, C, Buckland, P I, and Gelfgren, S 2020 Mapping SocioEcological Landscapes: Geovisualization as method. In Routledge International Handbook of Research Methods in Digital Humanities (1st ed., pp. 203-217). London and New York: Routledge.

Habicht, C 1985 Pausanias' Guide to Ancient Greece. Sather Classical Lectures. Berkeley.

Harrison, Rodney 2013 Forgetting to remember, remembering to forget: Late modern heritage practices, sustainability and the 'crisis' of accumulation of the past. International Journal of Heritage Studies, 19(6): 579-595.

Hodder, I 1993 The narrative and rhetoric of material culture sequences. WorldArch, 25: 268-282.

Hutton, W 2005 Describing Greece: Landscape and Literature in the Periegesis of Pausanias. Cambridge.

Konstan, D 2001 To Hellēnikon Ethnos: Ethnicity and the Construction of Ancient Greek Identity. In I. Malkin (Ed.), Ancient Perceptions of Greek Ethnicity (pp. 29-50). Cambridge, Massachusetts, USA: Harvard University Press.

Lundqvist, K, and Landeschi, G 2015 From CIL to 2D and 3D GIS. Archeologia e Calcolatori, 26: 25-27.

Palladino, C 2016 New Approaches to Ancient Spatial Models: Digital Humanities and Classical Geography. Bulletin of the Institute of Classical Studies, 59(2): 56-70.

Pretzler, M 2007 Pausanias: Travel Writing in Ancient Greece. London.

Simon, R, Barker, E, and Isaksen, L 2012 Exploring Pelagios: A visual browser for geo-tagged datasets.

Stewart, D R 2013 “Most worth remembering”: Pausanias, analogy, and Classical Archaeology. Hesperia: The Journal of the American School of Classical Studies at Athens, 82(2): 231-261. 